\title{
Silicon Nanocrystals with pH-Sensitive Tunable Light Emission from Violet to Blue-Green
}

\author{
Jing Wang ${ }^{1,2,3, *}$, Junhong Guo ${ }^{1,2}$ and Jing Chen ${ }^{1,2,3}$ \\ 1 Department of Electronic Science and Engineering, Nanjing University of Posts and Telecommunications, \\ Nanjing 210003, China; jhguo@njupt.edu.cn (J.G.); jchen@njupt.edu.cn (J.C.) \\ 2 National Laboratory of Solid State Microstructures and Department of Physics, Nanjing University, \\ Nanjing 210093, China \\ 3 Jiangsu Provincial Engineering Laboratory for RF Integration and Micropackaging, Xinmofan Street 66, \\ Nanjing 210003, China \\ * Correspondence: IreneWang@njupt.edu.cn; Tel.: +86-13913875497
}

Received: 4 September 2017; Accepted: 20 October 2017; Published: 20 October 2017

\begin{abstract}
We fabricated a silicon nanocrystal (NC) suspension with visible, continuous, tunable light emission with $\mathrm{pH}$ sensitivity from violet to blue-green. Transmission electron microscopy (TEM) images and X-ray diffraction (XRD) pattern analysis exhibit the highly crystalline nanoparticles of silicon. Photoluminescence (PL) spectra and photoluminescence excitation (PLE) spectra at different $\mathrm{pH}$ values, such as $1,3,5,7,9$, and 11, reveal the origins of light emission from the silicon NC suspension, which includes both the quantum confinement effect and surface bonding. The quantum confinement effect dominates the PL origins of silicon NCs, especially determining the tunability and the emission range of $\mathrm{PL}$, while the surface bonding regulates the maximum peak center, full width at half maximum (FWHM), and offsets of PL peaks in response to the changing $\mathrm{pH}$ value. The peak fitting of PLE curves reveals one of the divided PLE peaks shifts towards a shorter wavelength when the $\mathrm{pH}$ value increases, which implies correspondence with the surface bonding between silicon NCs and hydrogen atoms or hydroxyl groups. The consequent detailed analysis of the PL spectra indicates that the surface bonding results in the transforming of the PL curves towards longer wavelengths with the increasing $\mathrm{pH}$ values, which is defined as the $\mathrm{pH}$ sensitivity of PL. These results suggest that the present silicon NCs with $\mathrm{pH}$-sensitive tunable light emission could find promising potential applications as optical sources, bio-sensors, etc.
\end{abstract}

Keywords: silicon; nanocrystals; pH sensitive; photoluminescence

\section{Introduction}

The research on low-dimensional silicon nanostructures is an active research field, due to the interesting chemical and physical properties [1-5]. Of all the low-dimensional silicon nanomaterials, the silicon NCs with a variety of types, such as porous silicon [6-8], silicon/ $\mathrm{SiO}_{2}$, or silicon/silicon nitride nuclear shell nanostructure [9-11], soluble quantum dots [12-17], silicon NC-based photonic crystal slabs [18], silicon NC ultrathin films [19], etc., have drawn increasing attention. In particular, the silicon NCs with intense light emission take up an important place in a large number of applications, including light-emitting sources [18,20,21], sensors [22], detectors [13,23,24], bio-tagging [22,25], bio-imaging [21,26], photovoltaics [27], optical communication [28], spintronics devices [29], etc.

Based on varied approaches of fabricating silicon NCs, including chemical vapor deposition [30], the non-thermal plasmas approach [20,31,32], electrochemical etching [13,32,33], chemical dissolution [16,34], annealing [35-37], pulsed laser ablation [15,38,39], and scanning transmission electron microscopic lithography [29], etc., various colors of silicon NC luminescence have been obtained, such as infrared [11,37], red [17,38], orange [13,40], yellow [16], green [13,41], 
blue [14-16,23,42-44], or multiple colors [21,45], etc. However, it is still a challenge to achieve controllable blue light emission of free silicon NCs without clustering, since the sizes of silicon NCs have to be much smaller than excitation Bohr radius of $4.3 \mathrm{~nm}$ [28] based on the quantum confinement effect $[15,30,46,47]$. On the other hand, the light emission from extensive origins suppress the luminescence originating from the quantum confinement effect as a result of the ultra-active surfaces of silicon NCs [48], although the sizes of NCs are small enough to show the quantum confinement effect $[6,49]$. Due to the high surface/volume ratio and the size confinement effects, the surface of silicon NCs are so active that they are often bonded to atoms or groups, such as hydrogen $[16,30,34,35,41,42,50]$, oxygen $[9,20,33,36,43,47]$, hydroxyl [46], or others [38]. Therefore, the blue luminescence that is often obtained is attributed to defects [44], surface states [48], interface localized states [36,43,51], oxidation [43], etc. There derives a question that, for silicon NCs with ultra-small sizes, such as $2 \mathrm{~nm}$, how do the bondings of NCs affect the light emission features? Free silicon NCs are often dispersed in different types of solvent, many of which have plenty of groups [5,52-55], such as methyl groups [32,54], 1-dodecene [54], etc., especially hydrogen atoms [54,56] or hydroxyl groups [56,57]. Since hydrogen atoms and hydroxyl groups are basic components of water and almost everywhere in cells, studying how the $\mathrm{pH}$ value influences the light emission of silicon NCs becomes significant. If the light emission characters of silicon NCs can be changed by simply adjusting the $\mathrm{pH}$ value, the silicon NCs will be widely applicable in bio-sensors [58], imaging [5], etc.

In this article, we report a pH-sensitive photoluminescence of silicon NCs, which covers from violet to blue-green. The bonds between surface silicon atoms of NCs and hydrogen atoms/hydroxyl groups make the PL transform towards longer wavelengths, corresponding to the increasing $\mathrm{pH}$ value, and the PL spectra are stronger in mild (neutral, weakly acidic, or alkalescent) environments than others, closer to the PL spectra based on the quantum confinement effect in silicon NCs. PLE curves group into two parts when the environment is alkaline. The cause of the $\mathrm{pH}$ sensitive photoluminescence is explored by the analysis of PLE peak fitting. It is inferred that there is a special state responsible for the surface bonding which causes the offsets of PL and PLE at different pH values, although the origins of light emission are dominated by the quantum confinement effect. Considering the mild intracellular environment, together with the biochemical processes in cells happening mostly in a narrow $\mathrm{pH}$ range, the present silicon NCs with the $\mathrm{pH}$-sensitive luminescence features from $\mathrm{pH}$ values 3 to 11 could find potential applications in a broad range, such as probes [23,54,58], monitors [17], tags $[5,17,21]$, etc.

\section{Materials and Methods}

Details of the synthesis process of the silicon NC suspension is illustrated in Figure 1. In brief, we first immerse $4.0 \mathrm{~g}$ silicon powder $(99.9 \%, 10 \mu \mathrm{m}$, Weiye Chemical Company, Ltd., Yancheng, China) in an ultrasonic bath for $30 \mathrm{~min}$, with $40 \mathrm{~mL}$ aqueous solution of $1 \mathrm{~mL}$ hydrofluoric acid (AR, $40.0 \%$ by volume, Macklin Company, Ltd., London, UK) and $0.02 \mathrm{~mL}$ nitric acid (AR, $65 \%$ by volume, Macklin Company, Ltd., London, UK). Thus, we obtained loose grains by corroding the silicon powder. After rinsing the corroded silicon powder with deionized water 4-5 times until the $\mathrm{pH}$ value of the supernatant liquid reaches 4 , we added $10 \mathrm{~mL}$ deionized water into the corroded silicon powder and continued the ultrasonic treatment for $60 \mathrm{~min}$. Finally the liquid as left to stand for at least $30 \mathrm{~min}$, and we obtained the supernatant fluid with silicon NCs suspended in it as our silicon NCs colloid sample. In the experiment, we can adjust the $\mathrm{pH}$ value of the silicon NC colloids by adding an aqueous solution of $\mathrm{HCl}(18 \%$ in mass diluted from the $36 \% \mathrm{HCL}(\mathrm{AR})$, produced by Xuhong Chemical Company, Ltd. Changzhou, China) and $\mathrm{NaOH}(20 \%$ in mass, from the $98 \% \mathrm{NaOH}(\mathrm{AR})$ pieces produced by Macklin Company, Ltd., London, UK). 
(a)

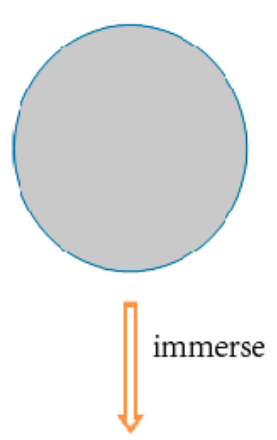

(b)

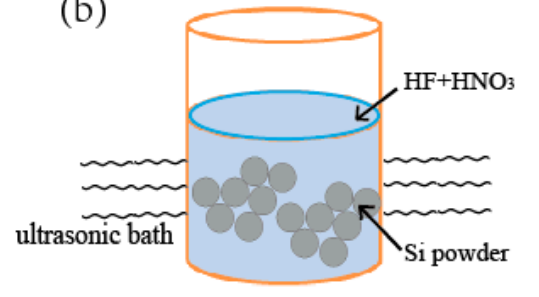

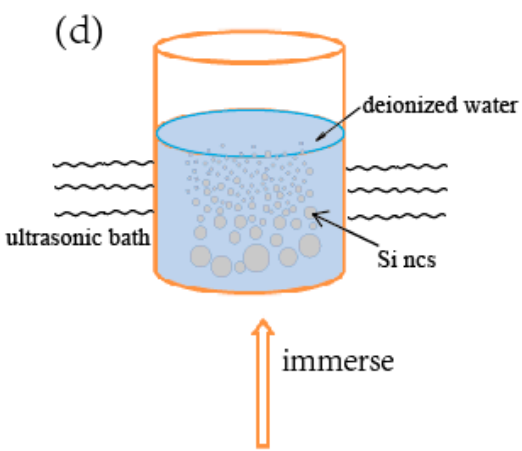

(c)

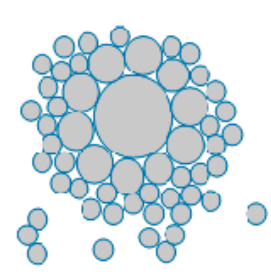

Figure 1. Schematic of the silicon NC fabrication process: (a) A grain of silicon powder; (b) silicon powder immersed in an ultrasonic bath with aqueous solution; (c) a silicon grain becomes loose after corroding; and (d) loose silicon grains are broken into suspended silicon NCs after another ultrasonic treatment with water.

Surface morphologies of silicon NCs were characterized by a JEOL JEM-2100 TEM after a drop of silicon suspension was dried on a piece of copper mesh. A quantity of silicon NC suspension was dried in a nitrogen atmosphere as the XRD sample. The XRD used in the present work is an ARL X'TRA diffractometer. The PL and PLE spectra were obtained by an FLS 920 fluorescence spectrometer (Edinburgh Instruments Company, Ltd., Edinburgh, UK), using a $450 \mathrm{~W}$ xenon lamp as the excitation optic source.

\section{Results and Discussion}

\subsection{Morphology Characterization and Size Statistics}

The TEM images of silicon NCs are taken at the accelerating voltage of $200 \mathrm{kV}$, as shown in Figure 2a. It is clearly seen that the silicon NCs appear close to spheres and disperse everywhere without gathering. We count the numbers of silicon NCs with different diameters from a number of TEM images. Most silicon NCs are between $1 \mathrm{~nm}$ and $4 \mathrm{~nm}$ in diameter, and no silicon NC larger than $4.5 \mathrm{~nm}$ is observed. The counting statistic with a Gauss fitting is shown in Figure 2d, suggesting that the most probable diameter is about $1.91 \mathrm{~nm}$. Since the silicon NCs smaller than $1 \mathrm{~nm}$ are easy to miss, the actual most probable diameter is probably much less than $1.91 \mathrm{~nm}$.

Figure 2b,c present the high-resolution TEM (HRTEM) images of silicon NCs, which display two highly-crystalline silicon NCs, with lattice fringes corresponding to (220) and (311) planes of silicon. As can be seen from Figure 2e, the sharp XRD line indicates the high crystallization and good monodispersion of silicon NCs, consistent with the HRTEM images, exhibiting typical peaks of silicon nanostructures $[12,44,59,60]$. 

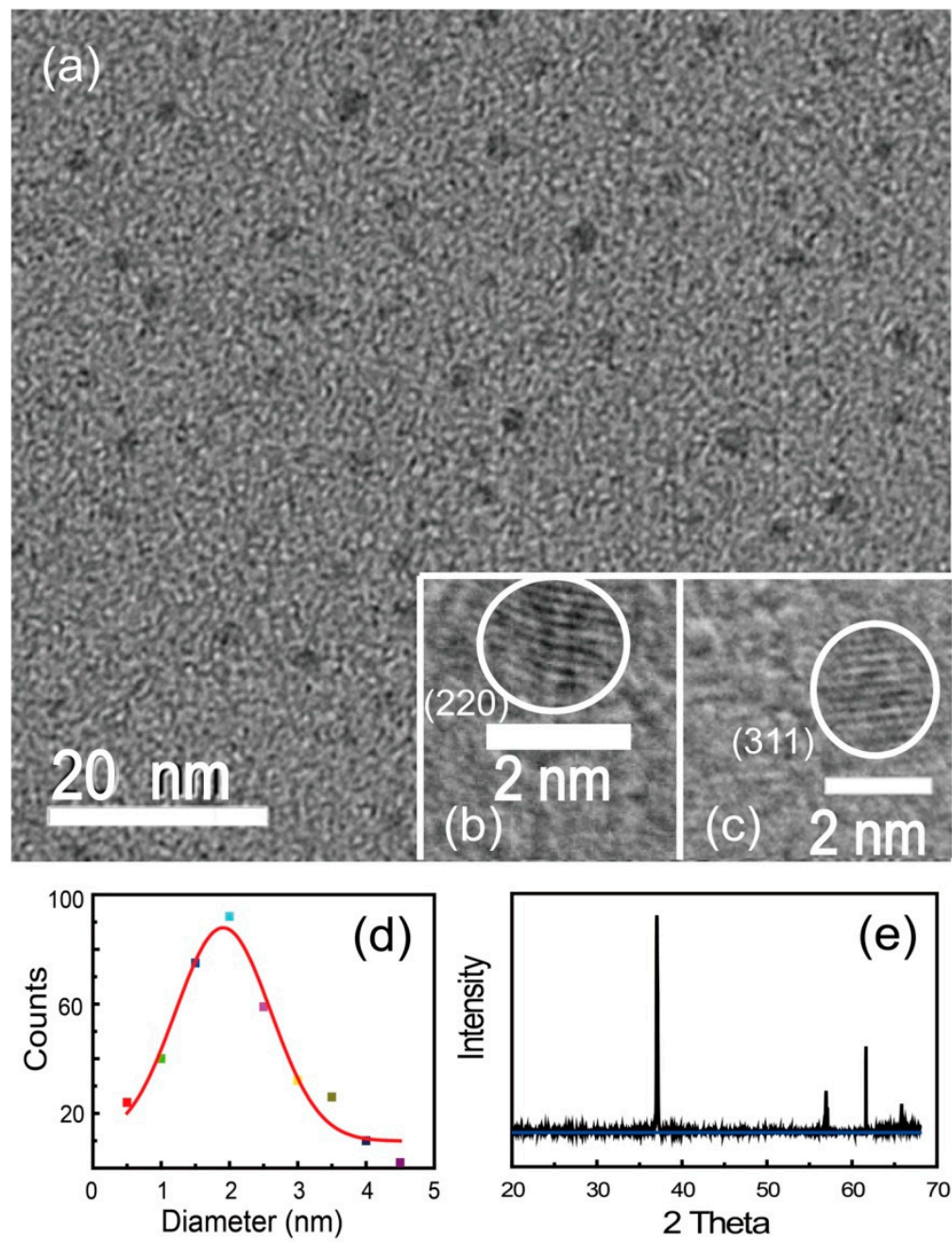

Figure 2. (a) A TEM image of silicon NCs; (b,c) HRTEM of silicon NCs, with lattice fringes corresponding to (220) and (311) planes of silicon; (d) size statistic of silicon NCs from a large number of TEM images. The most probable size of $1.91 \mathrm{~nm}$ is calculated according to Gaussian fitting, as the curve shows; and (e) XRD line of silicon NCs.

\subsection{PL and PLE Spectral Characteristic}

We study the PL spectra and PLE spectra acquired from silicon NC colloids with different $\mathrm{pH}$ values in detail. As shown in Figure 3a, the PL spectra from silicon NC colloids with an unadjusted pH value, which is 4 , indicate the strongest PL peak responding to the excitation wavelength of $325 \mathrm{~nm}$. There is a redshift in the light emission with the increasing excitation wavelength. When the excitation wavelength varies from $320 \mathrm{~nm}$ to $420 \mathrm{~nm}$, the PL peak wavelength increases from $400 \mathrm{~nm}$ to $520 \mathrm{~nm}$. When silicon NCs with probable size can always be excited by the wavelengths smaller than $325 \mathrm{~nm}$, the intensity of PL peak increases. As the number of silicon NCs which can be excited decreases along with continuing increase of excitation wavelength, the PL intensity reduces and a small water Raman peak appears. According to Wolkin's model [6] the most probable diameter can be estimated from the most intensive PL peak wavelength, which is around $1.8 \mathrm{~nm}$, agreeing with the size statistic shown in Figure 2d. Despite the bulk silicon band gap is $1.12 \mathrm{eV}(1107 \mathrm{~nm})$, the PL signal is too weak to be observed beyond the emission wavelength $510 \mathrm{~nm}$, implying the absence of silicon NCs larger than $4 \mathrm{~nm}$ in diameter, which is also consistent with Figure 2d. Since most of silicon NCs are much smaller than the excitation Bohr radius of bulk silicon around $4.3 \mathrm{~nm}$ [22], we can conclude that the redshift along with increasing excitation wavelength is attributed to the quantum confinement effect in silicon 
NCs. The redshift of PLE peak center accompanied by increasing emission wavelength, as shown in Figure $3 b$, further confirm the result that the quantum confinement effect results in the tunable light emission of silicon NCs. Figure 3c,d show the optic photos of lighting silicon NC colloids at the exciting wavelength of $360 \mathrm{~nm}$ and $420 \mathrm{~nm}$, respectively. It is evident that the light emission of the resulted silicon NCs colloid is strong enough to be observed by the naked eye.
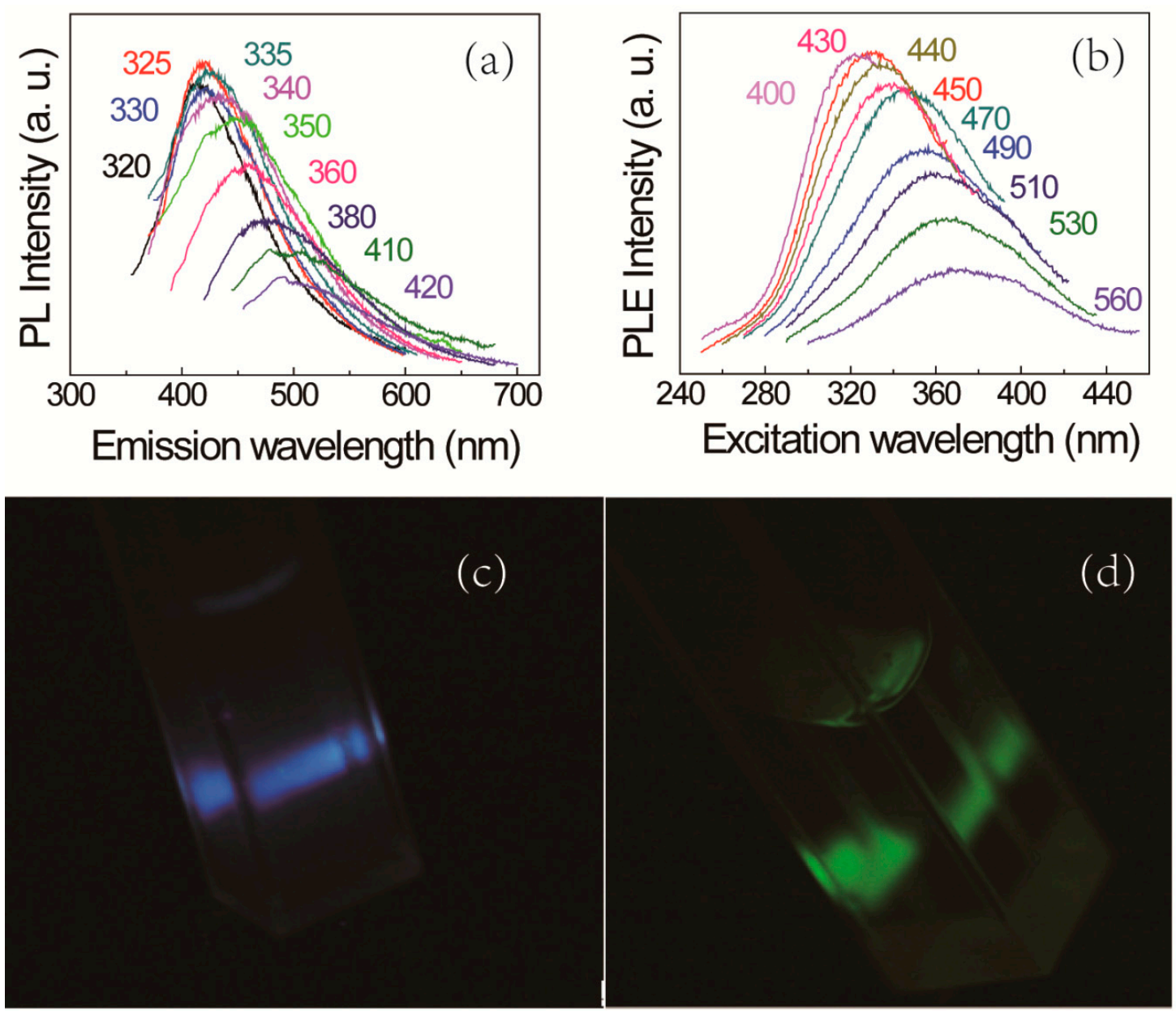

Figure 3. (a) PL spectra of silicon NCs colloid with pH value of 4; (b) PLE spectra of silicon NCs colloid with $\mathrm{pH}$ value of 4; (c) optical photograph obtained from silicon NC colloids excited at $360 \mathrm{~nm}$, corresponding to blue ( $450 \mathrm{~nm})$; and (d) optical photograph from silicon NCs colloid excited at $420 \mathrm{~nm}$, corresponding to green color $(\sim 510 \mathrm{~nm})$.

The redshift of the PL peak with increasing excitation wavelength can also be observed from silicon NC colloids with pH 1, 3, 5, 7, 9 and 11, as shown in Figure 4(a1-a6). After pH 11, the PL spectrum is difficult to analyze due to the chaotic and weak curves, which is not exhibited in the figure. As can be seen, the light emission is still visible, and the emission wavelength gradually redshifts from $400 \mathrm{~nm}$ to $500 \mathrm{~nm}$ with the excitation wavelength increasing from $320 \mathrm{~nm}$ to $430 \mathrm{~nm}$. If we take the PL spectrum shown in Figure $3 \mathrm{a}$ as a basic spectrum, the offsets of PL peaks corresponding to the same excitation wavelength in Figure 4a1-a6 vary from approximately $5 \mathrm{~nm}$ to $25 \mathrm{~nm}$. As a result, the PL shapes in Figures 3 and 4 are similar despite on the various $\mathrm{pH}$ values of silicon NC colloids, meaning that the quantum confinement effect plays the most important role in the light emission of silicon NCs. However, besides the offsets of PL peaks, the PL peak center reaches the maximum intensity at 320,

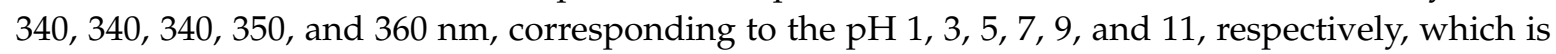
difficult to be interpreted as the quantum confinement effect. With increasing $\mathrm{pH}$ values, not only 
the maximum PL peak, but also nearly every PL curve at the same excitation wavelength, transforms toward longer wavelengths, as displayed in Table 1 (based on Figure 4(a1-a6)), and the PL FWHM at the same excitation wavelength becomes wider. The PL peaks shift toward longer wavelengths, which we define as the $\mathrm{pH}$ sensitivity of photoluminescence, showing that the light emission of silicon NCs could be influenced by the chemical environment.
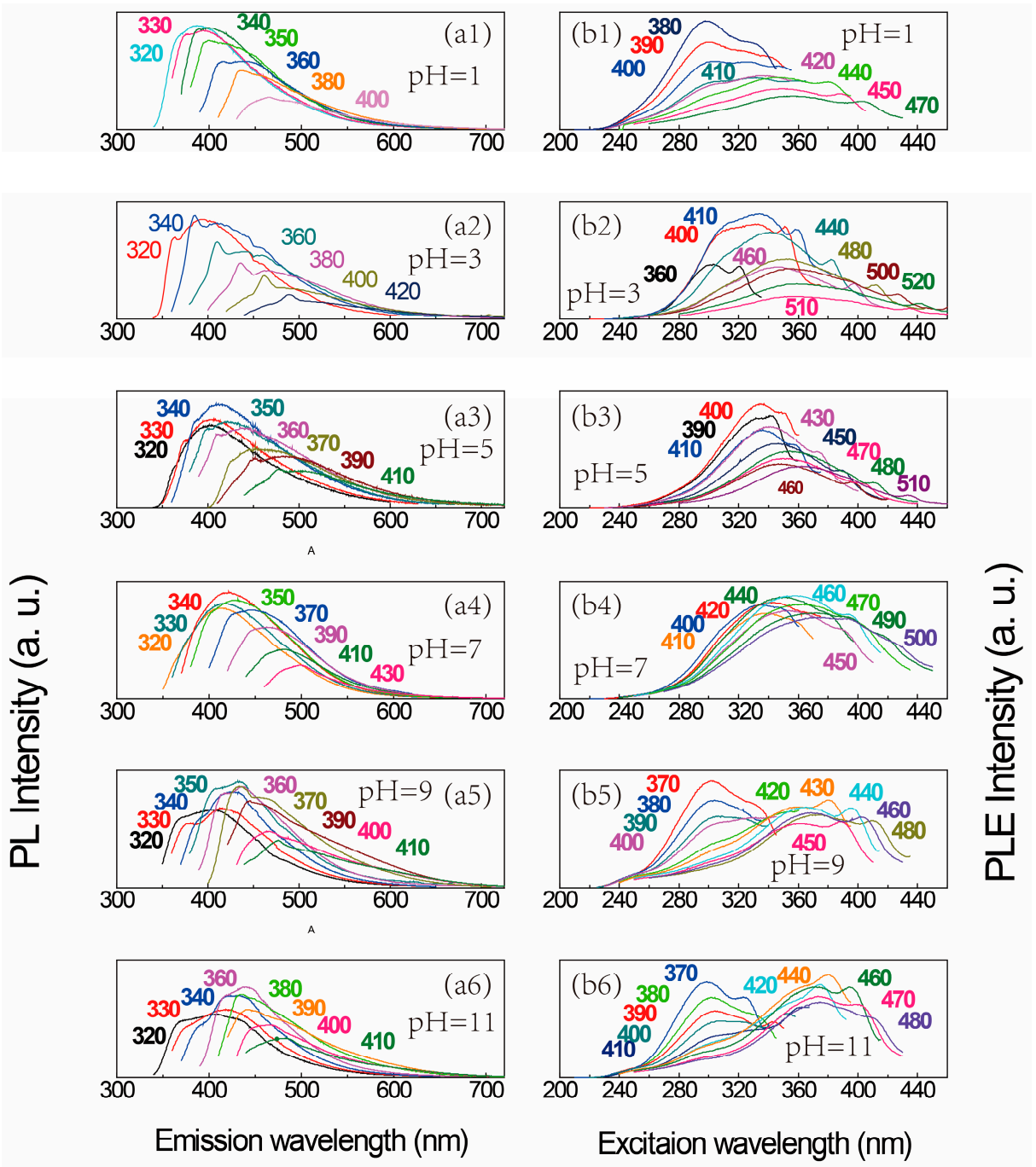

Figure 4. PL spectra from silicon NCs colloid with pH values of (a1) 1, (a2) 3, (a3) 5, (a4) 7, (a5) 9, and (a6) 11. PLE spectra from silicon NCs colloid with pH values of (b1) 1, (b2) 3, (b3) 5, (b4) 7, (b5) 9, and (b6) 11 .

Table 1. The center wavelengths of PL peaks at different $\mathrm{pH}$ values corresponding to various excitation wavelengths.

\begin{tabular}{ccccccc}
\hline PL Peak Wavelength & $\mathbf{p H}=\mathbf{1}$ & $\mathbf{p H}=\mathbf{3}$ & $\mathbf{p H}=\mathbf{5}$ & $\mathbf{p H}=\mathbf{7}$ & $\mathbf{p H}=\mathbf{9}$ & $\mathbf{p H}=\mathbf{1 1}$ \\
\hline 320 & 381 & 390 & 400 & 405 & 402 & 410 \\
340 & 400 & 407 & 412 & 420 & 424 & 429 \\
350 & - & - & 414 & 425 & - & - \\
360 & 430 & 433 & 436 & - & 443 & 447 \\
370 & - & - & 450 & 450 & 450 & - \\
380 & 455 & 460 & - & - & - & - \\
390 & - & - & 460 & 464 & 462 & 464 \\
\hline
\end{tabular}


PLE spectra of silicon NCs colloid with different $\mathrm{pH}$ values are presented in Figures $3 \mathrm{~b}$ and 4(b1-b6). In Figure 3b, the PLE peak wavelength increase monotonically with the excitation wavelength, as well as Figure $4(\mathrm{~b} 3, \mathrm{~b} 4)$ indicate, implying that the same wavelength can excite silicon NCs with different sizes. However, the shift of the PLE peak cannot be easily observed when the $\mathrm{pH}$ value is 1 or 3, as shown in Figure 4(b1,b2), because there is a raised shoulder in the PLE curve around the excitation wavelength of $300 \mathrm{~nm}$. Considering the acidic environment, it is inferred that the shoulder is related to the surface bonding between silicon NCs and hydrogen atoms. Similar to Figure 3b, a small redshift of the PLE peak with the increasing emission wavelength can be observed in the long wavelength area (which is from $420 \mathrm{~nm}$ to $470 \mathrm{~nm}$ in Figure 4(b1) and is from $440 \mathrm{~nm}$ to $500 \mathrm{~nm}$ in Figure 4(b2)), suggesting that the light emission feature could be influenced by an acidic environment only in the high energy part. The PLE spectrum in Figure 4(b5,b6) displays more significant differences from the others. The PLE curves separate into two groups. PLE curves in group 1 are assembled near the ultraviolet area, approximately covering from $250 \mathrm{~nm}$ to $350 \mathrm{~nm}$ in excitation wavelength, in response to an emission wavelength from $370 \mathrm{~nm}$ to $410 \mathrm{~nm}$. No obvious shift is observed, but the PLE peak is gradually weakened with the rising emission wavelength. Compared to group 1 , the PLE peak suddenly rise at the emission wavelength of $420 \mathrm{~nm}$, meaning two origins of silicon NC's light emission. PLE curves in this group (group 2) include a few curves located in the violet-blue area, with PLE peaks from $350 \mathrm{~nm}$ to $400 \mathrm{~nm}$, corresponding to emission wavelengths from $420 \mathrm{~nm}$ to $480 \mathrm{~nm}$. A small redshift of the PLE peak can be observed in pace with increasing emission wavelength, accompanied by decreasing intensity and width. The shape and location of the PLE curves in group 2 are similar to the ones in Figure 3b, matching the PL spectrum in Figure 4(a5,a6), respectively, much better than group 1. It seems that an alkaline environment influences the PLE performance more in the short wavelength region, consistent with the PL spectra.

The PLE spectra with the features above suggest two origins of silicon NC photoluminescence. At different $\mathrm{pH}$ values, it will be found that a typical PLE curve (picking from Figure 4(b1-b6)) such as that shown in Figure 5a-f could be divided into two peaks by peak fitting besides the Raman peak of water. A typical PLE curve should be representative and strong enough for peak fitting. Therefore, for a $\mathrm{pH}$ value 1 , the curve of a $450 \mathrm{~nm}$ emission wavelength is chosen and for $\mathrm{pH}$ values of 3, 5, 7, 9, and 11 , the curves at the emission wavelengths of $470 \mathrm{~nm}$ or $480 \mathrm{~nm}$ are chosen. The center wavelengths of two divided peaks at different $\mathrm{pH}$ values are listed in Table 2. It is observed that, at the same emission wavelength, one of the peaks (divided peak 1 ) redshifts with the $\mathrm{pH}$ value increasing from 1 to 11 and the other peak (divided peak 2) has a shortening center wavelength with the $\mathrm{pH}$ value increasing (the divided peak 2 does not appear at $\mathrm{pH} 1$ ). The divided peak 2 is not visible when the $\mathrm{pH}$ is 1 , as shown in Figure 5a, maybe because the divided peak 2 should be longer than $400 \mathrm{~nm}$, beyond the range of the PLE. The shift of divided peak 1 with an increasing $\mathrm{pH}$ value is far less intense than the shift of the divided peak 2 and the divided peak 1 . Considering the center wavelength of the divided peak 1 , as well, it is reasonable to conclude that divided peak 1 is due to the quantum confinement effect [46], while the divided peak 2 is inferred to be based on the surface bonding between silicon NCs and hydrogen atom or hydroxyl group. The divided peak 2 appears more intense in the short emission wavelength range (shorter than $410 \mathrm{~nm}$, roughly), especially in an alkaline environment. As a result, when the $\mathrm{pH}$ value is 9 or 11 , responding to the same emission wavelengths, the peak wavelengths of the group 1 PLE curves are shorter compared to the PLE peak wavelengths at $\mathrm{pH} 1-7$, while the peak wavelengths of the group 2 PLE curves are longer. Therefore, it is explained that the grouping of PLE curves at the $\mathrm{pH}$ values 9 or 11 is a result of the divided peak 2 redshift to the short wavelength area. Although distinct grouping cannot be observed in the PLE curves at $\mathrm{pH} 1-7$, we can still find clues suggesting the two origins of the silicon NC photoluminescence, which is consistent with the PLE spectra of $\mathrm{pH} 9$ and 11 . As Figure 5b1-b4 shows, when the $\mathrm{pH}$ value is $1,3,5$, or 7 , the divided peak 2 is in a longer wavelength area, which cannot show the obvious grouping of PLE curves. When the emission wavelength is the same, the PLE peak wavelength at $\mathrm{pH} 1$ is shorter than it is at $\mathrm{pH} 3$ and the PLE peak wavelength at $\mathrm{pH} 3$ is shorter than it is at $\mathrm{pH} 5$, etc., meaning the divided peak 1 
is dominant in an acid environment and divided peak 2 gradually shows its power as the $\mathrm{pH}$ value increases, and is even weak in a neutral environment. Thus, we can conclude that the PLE patterns at different $\mathrm{pH}$ values are the combined effect of the divided peaks 1 and 2 . In another word, the PL of silicon NCs originates both from the quantum confinement effect and the surface bonding between NCs and hydrogen atoms or hydroxyl groups. Another result of this combined effect is that, in the low energy area, the PL and PLE curves show more intense changes compared to a neutral environment.
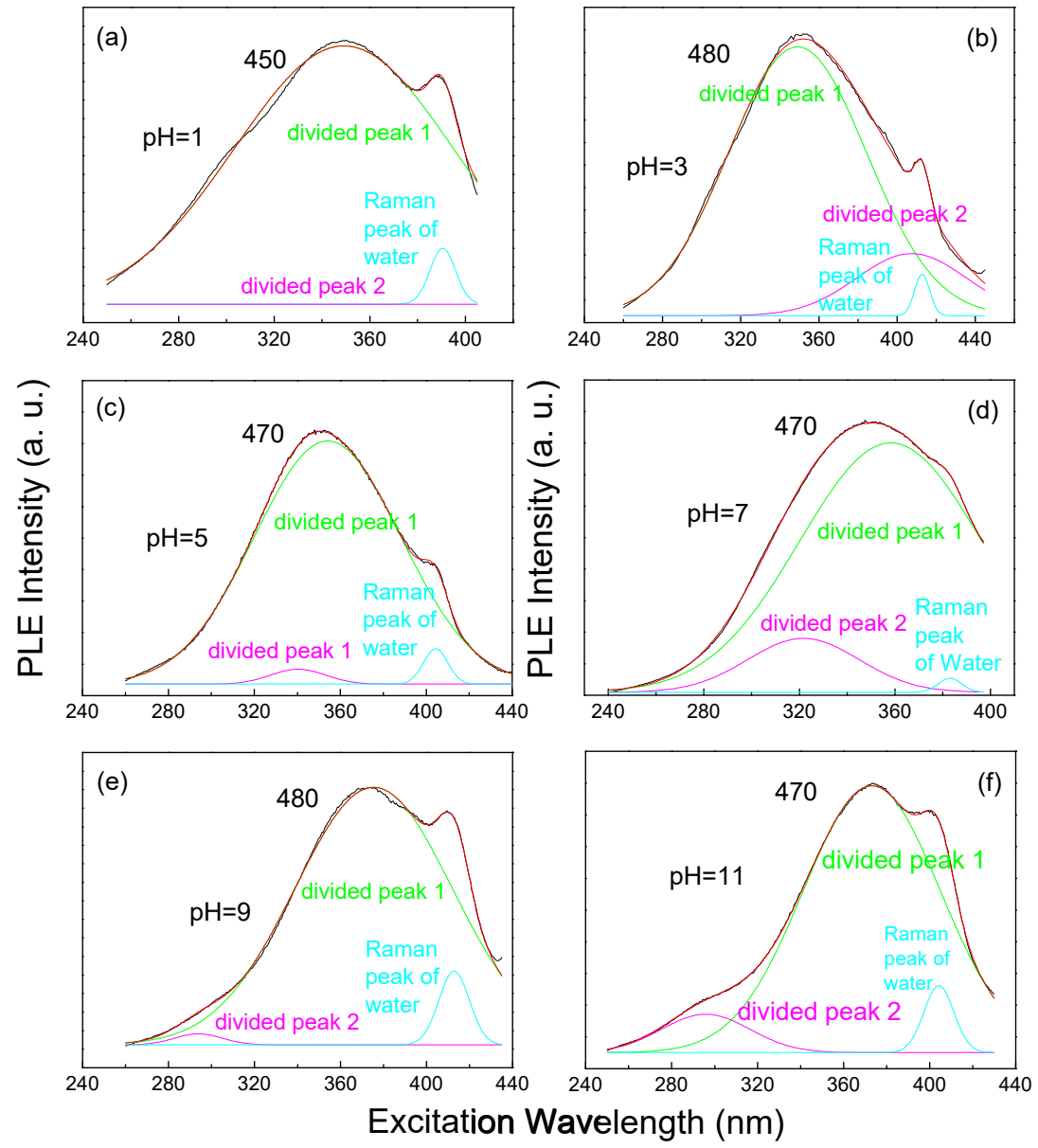

Figure 5. Gauss fitting of PLE spectra with the silicon NC colloid $\mathrm{pH}$ values at (a) 1, at the emission wavelength $450 \mathrm{~nm}$; (b) 3, at the emission wavelength $480 \mathrm{~nm}$; (c) 5, at the emission wavelength $470 \mathrm{~nm}$; (d) 7, at the emission wavelength $470 \mathrm{~nm}$; (e) 9, at the emission wavelength $480 \mathrm{~nm}$; and (f) 11, at the emission wavelength $470 \mathrm{~nm}$.

Table 2. The center wavelengths of two divided peaks corresponding to typical PLE curves at different $\mathrm{pH}$ values.

\begin{tabular}{cccc}
\hline pH Value & Emission Wavelength $(\mathbf{n m})$ & $\begin{array}{c}\text { Center Wavelength of } \\
\text { Divided Peak } \mathbf{1}\end{array}$ & $\begin{array}{c}\text { Center Wavelength of } \\
\text { Divided Peak 2 }\end{array}$ \\
\hline 1 & 450 & 349 & N/A \\
3 & 480 & 355 & 405 \\
5 & 470 & 358 & 343 \\
7 & 470 & 361 & 322 \\
9 & 480 & 375 & 297 \\
11 & 470 & 373 & 293 \\
\hline
\end{tabular}


The comparison among PLE spectra at different $\mathrm{pH}$ values implies that once the acid environment disappears, the divided peak 2 shifts to a shorter wavelength area, which is more effective in the higher energy part, resulting in a strong grouping of PLE curves in an alkaline environment. Based on the analysis of the PLE spectra above, the PL transforming towards longer wavelengths is easy to understand. Based on the statistics in Table 2, the shift of the divided peak 1 is not obviously corresponding to the same emission wavelength when the $\mathrm{pH}$ value changes. Thus, the change of the PLE curve patterns responsible for the $\mathrm{pH}$ value increasing depends mainly on the divided peak 2 . The divided peak 2 shifts towards the shorter wavelength with the increasing $\mathrm{pH}$ value, meaning the corresponding excitation wavelength is longer at the same emission wavelength. That is, when the $\mathrm{pH}$ value increases, the emission wavelength shifts towards longer wavelengths at the same excitation wavelength. In another word, the PL peak will shift toward a longer wavelength in pace with the ascending $\mathrm{pH}$ value.

All of the above features of the PL and PLE spectra indicate that both strong acidic and alkalescent environment can greatly change the characteristics of silicon NC colloid photoluminescence, which means some electron states are formed based on the dangling bonds between hydrogen atoms or hydroxyl groups and silicon atoms on the NCs' surfaces, although the quantum confinement effect dominates the light emission of silicon NCs, consistent with Figures 3a and 4(a4). The high energy part is influenced greatly by the chemical environment, indicating that smaller silicon NCs with more active surfaces could produce dangling bonds more easily. Smaller NCs have rough surfaces, which makes them bond more to hydroxyl groups. This is why the divided peak 2 from the PLE curve is more effective in the higher energy part. It consequently implies that the content of hydrogen atom and hydroxyl group bonding to NCs' surfaces influence the light emission properties. It is found that when the content of hydrogen atoms and hydroxyl groups achieve a rough balance, the spectra appears as a typical effect of quantum confinement [46], and the light emission properties reach an optimum with a wider emission range and higher intensity, comparatively. Based on the near-neutral environment in biological cells, the silicon NCs could be applied to tracing biological processes, keeping their intrinsic characteristics. Since weak acidity-alkalinity switching often happens in bio-cells, the $\mathrm{pH}$ sensitivity of silicon NCs' luminescence in the routine pH range from 1 to 11 of the cell environment $[60,61]$ is probably helpful for monitoring biological processes.

\section{Conclusions}

We have demonstrated that, by monodispersed ultra-small silicon NCs with active surfaces, the tunable photoluminescence from violet to blue-green with $\mathrm{pH}$ sensitivity is observed due to both the quantum confinement effect and the bonding interaction between silicon atoms on the NCs' surfaces and hydrogen atoms or hydroxyl groups. It is discovered that there is a special surface state based on the bonding between silicon NCs and hydroxyl groups, which creates a large effect in an alkaline environment, widening the PL and PLE curves, driving PL curves to transform towards longer wavelengths with the increasing $\mathrm{pH}$ value. In a word, the quantum confinement effect makes the silicon NCs show tunable violet-blue-green photoluminescence, while the surface state makes the photoluminescence sensitive to the $\mathrm{pH}$ value. The exploration of the $\mathrm{pH}$ sensitivity of silicon NCs' luminescence could help further research about the effects of surface bonding on the energy states, such as $\mathrm{pH}$ sensitivity of other silicon nanostructures, or more complicated groups bonding to silicon NCs, even groups bonding to other silicon-based nanomaterials, etc. The tunable photoluminescence make silicon NCs possible to work as optical sources [26], nano-optoelectronic devices [62,63], nano-optoelectronic devices, and intracellular tracing [62]. Additionally, the pH sensitivity of luminescence from silicon NCs makes it possible to realize real-time monitoring on biological processes in cells $[62,64]$. Since hydrogen and hydroxyl appear nearly everywhere in biology cells and participate in most biochemical processes, the silicon NCs bonding with hydrogen or hydroxyl show excellent bio-compatibility that they are easy to enter bio-cells without rejection $[5,24,62]$, providing a beautiful prospect in bio-probes and bio-sensors, even bio-light emitters. Furthermore, 
considering the multiple PL colors from the silicon NCs, it is also possible to monitor the $\mathrm{pH}$ value, which can greatly help us understand detailed processes in chemical or biochemical reactions.

Acknowledgments: This work was supported by the National Natural Science Foundation of China (grant nos. 51302136 and 11304159), the Natural Science Foundation of Jiangsu Province (grant no. BK20161512), the Qing Lan Project of Jiangsu Province, and Nanjing University of Posts and Telecommunications Research Fund (nos. NY213017 and NY217045). The authors sincerely appreciate X. L. Wu and J. C. Shen in the School of Physics, Nanjing University, for the supports on PL measurement.

Author Contributions: J. Wang conceived the research, collected all data, interpreted the results, and wrote the manuscript; J. Guo conceived the research and designed the experiments; and J. Chen analyzed the results and co-wrote the manuscript. All authors read and approved the final manuscript.

Conflicts of Interest: The authors declare no conflict of interest. The founding sponsors had no role in the design of the study; in the collection, analyses, or interpretation of data; in the writing of the manuscript, and in the decision to publish the results.

\section{Appendix}

Figure A1 is an example to show the redshift of divided peak 1 in response to the increasing excitation wavelength. The centered wavelength of divided peak 1 at the excitation wavelength $460 \mathrm{~nm}$ is $370 \mathrm{~nm}$, as Figure A1a shows, while the centered wavelength at the excitation wavelength $480 \mathrm{~nm}$ is $377 \mathrm{~nm}$, as Figure A1b shows.

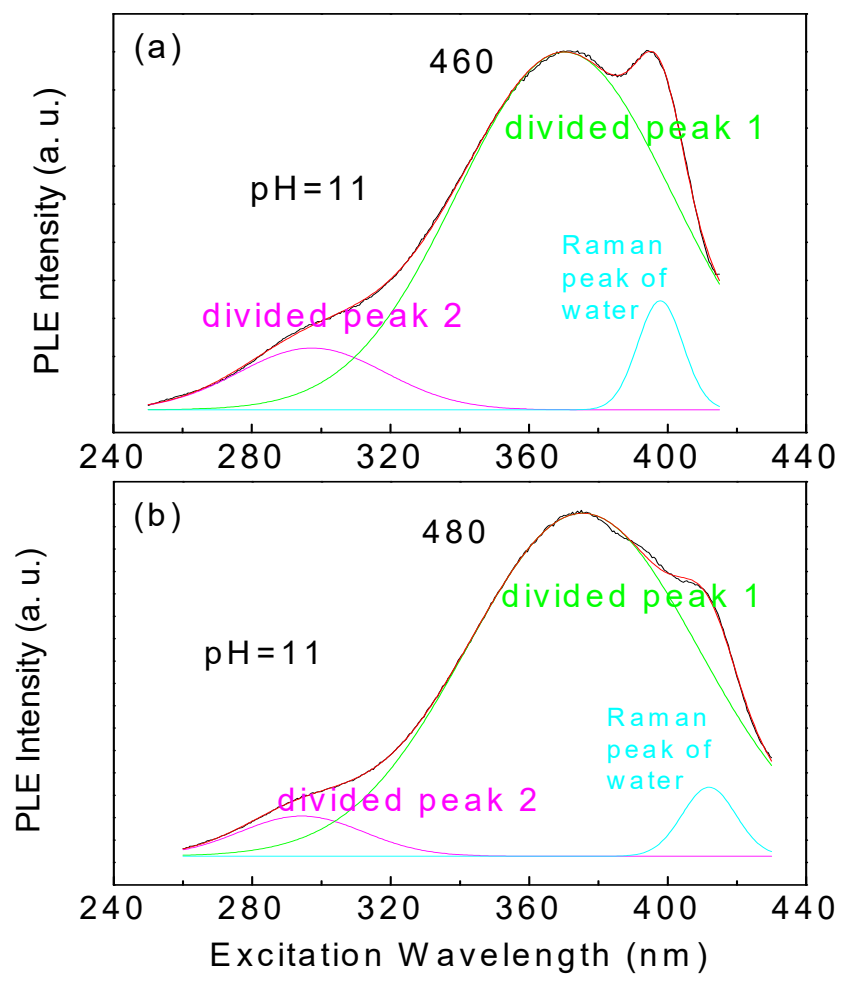

Figure A1. Gauss fitting of the PLE spectra at the emission wavelength of (a) 460 and (b) $480 \mathrm{~nm}$ when the $\mathrm{pH}$ value of silicon NCs colloid is 11 .

\section{References}

1. Kim, U.; Kim, I.; Park, Y.; Lee, K.Y.; Yim, S.Y.; Park, J.G.; Ahn, H.G.; Park, S.H.; Choi, H.J. Synthesis of Si Nanosheets by a Chemical Vapor Deposition Process and Their Blue Emissions. ACS Nano 2011, 5, 2176-2181. [CrossRef] [PubMed]

2. Zhuang, L.; Guo, L.; Chou, S.Y. Silicon single-electron quantum-dot transistor switch operating at room temperature. Appl. Phys. Lett. 1998, 72, 1205-1207. [CrossRef] 
3. Cui, Y.; Lieber, C.M. Functional nanoscale electronic devices assembled using silicon nanowire building blocks. Science 2001, 291, 851-853. [CrossRef] [PubMed]

4. Huang, M.H.; Mao, S.; Feick, H.; Yan, H.; Wu, Y.; Kind, H.; Weber, E.; Russo, R.; Yang, P. Room-temperature ultraviolet nanowire nanolasers. Science 2001, 292, 1897-1899. [CrossRef] [PubMed]

5. Erogbogbo, F.; Yong, K.T.; Roy, I.; Xu, G.; Prasad, P.N.; Swihart, M.T. Biocompatible luminescent silicon quantum dots for imaging of cancer cells. ACS Nano 2008, 2, 873-878. [CrossRef] [PubMed]

6. Wolkin, M.V.; Jorne, J.; Fauchet, P.M. Electronic states and luminescence in porous silicon quantum dots: The role of oxygen. Phys. Rev. Lett. 1999, 82, 197-200. [CrossRef]

7. Cullis, A.G.; Canham, L.T.; Calcott, P.D.J. The structural and luminescence properties of porous silicon. J. Appl. Phys. 1997, 82, 909-965. [CrossRef]

8. Canham, L.T. Silicon quantum wire array fabrication by electrochemical and chemical dissolution of wafers. Appl. Phys. Lett. 1990, 57 (Suppl. 10), 1046-1048. [CrossRef]

9. Hao, X.J.; Podhorodecki, A.P.; Shen, Y.S.; Zatryb, G.; Misiewicz, J.; Green, M.A. Effects of Si-rich oxide layer stoichiometry on the structural and optical properties of $\mathrm{Si} \mathrm{QD/SiO} 2$ multilayer films. Nanotechnology 2009, 20, 485703-485712. [CrossRef] [PubMed]

10. Holunga, D.M.; Flagan, R.C.; Atwater, H.A. A scalable turbulent mixing aerosol reactor for oxide-coated silicon nanoparticles. Ind. Eng. Chem. Res. 2005, 44, 6332-6341. [CrossRef]

11. Littau, K.A.; Szajowski, P.J.; Muller, A.J.; Kortan, A.R.; Brus, L.E. A luminescent silicon nanocrystal colloid via a high-temperature aerosol reaction. J. Phys. Chem. 1993, 97, 1224-1230. [CrossRef]

12. Lopez, J.A.L.; Roman, A.G.; Barojas, E.G.; Gracia, J.F.F.; Juarez, J.M.; Lopez, J.C. Synthesis of colloidal solutions with silicon nanocrystals from porous silicon. Nanoscale Res. Lett. 2014, 9, 571-582. [CrossRef] [PubMed]

13. Valenta, J.; Jenada, P.; Dohnalová, K.; Niznansky, D.; Vácha, F.; Linnros, J. Colloidal suspensions of silicon nanocrystals: From single nanocrystals to photonic structures. Opt. Mater. 2005, 27 (Suppl. 5), 1046-1049. [CrossRef]

14. Tilley, R.D.; Warner, J.H.; Yamamoto, K.; Matsui, I.; Fujimori, H. Micro-emulsion synthesis of monodisperse surface stabilized silicon nanocrystals. Chem. Commun. 2005, 14, 1833-1835. [CrossRef] [PubMed]

15. Umezu, I.; Minami, H.; Senoo, H.; Sugimura, A. Synthesis of photoluminescent colloidal silicon nanoparticles by pulsed laser ablation in liquids. J. Phys. 2007, 59 (Suppl. 1), 392-395. [CrossRef]

16. Bagabas, A.A.; Gondal, M.A.; Dastageer, M.A.; Al-Muhanna, A.A.; Alanazi, T.H.; Ababtain, M.A. A study of laser-induced blue emission with nanosecond decay of silicon nanoparticles synthesized by a chemical etching method. Nanotechnology 2009, 20, 355703. [CrossRef] [PubMed]

17. Yixuan, Y.; Clare, E.R.; Richard, D.S.; Brian, A.K. Synthesis and Ligand Exchange of Thiol-capped Silicon Nanocrystals. Langmuir 2015, 31, 6886-6893. [CrossRef]

18. Ondic, L.; Varga, M.; Pelant, I.; Valenta, J.; Kromka, A.; Elliman, R.G. Silicon nanocrystal-based photonic crystal slabs with broadband and efficient directional light emission. Sci. Rep. 2017, 7, 5763. [CrossRef] [PubMed]

19. Svrcek, V.; McDonald, C.; Lozac'h, M.; Tayagaki, T.; Koganezawa, T.; Miyadera, T.; Mariotti, D.; Matsubara, K. Stable ultrathin surfactant-free surface-engineered silicon nanocrystal solar cells deposited at room temperature. Energy Sci. Eng. 2017, 5, 184-193. [CrossRef]

20. Cheng, K.; Anthony, R.; Kortshagen, U.; Holmes, R. High-Efficiency Silicon Nanocrystal Light-Emitting Devices. Nano Lett. 2011, 11, 1952-1956. [CrossRef] [PubMed]

21. Bruhn, B.; Brenny, B.J.M.; Dekker, S.; Dogan, I.; Schall, P.; Dohnalova, K. Multi-chromatic silicon nanocrystals. Light Sci. Appl. 2017, 6, e17007. [CrossRef]

22. Chaabane, N.; Cabarrocas, P.R.; Vach, H. Trapping of plasma produced nanocrystalline Si particles on a low temperature substrate. J. Non-Cryst. Solids 2004, 338, 51-55. [CrossRef]

23. Nayfeh, M.H.; Rao, S.; Nayfeh, O.M.; Smith, A.; Therrien, J. UV photodetectors with thin-film Si nanoparticle active medium. IEEE Trans. Nanotechnol. 2005, 4 (Suppl. 6), 660-668. [CrossRef]

24. Erogbogbo, F.; Yong, K.T.; Hu, R.; Law, W.C.; Ding, H.; Chang, C.W.; Prasad, P.N.; Swihart, M.T. Biocompatible Magnetofluorescent Probes: Luminescent Silicon Quantum Dots Coupled with Superparamagnetic Iron(III) Oxide. ACS Nano 2010, 4, 5131-5138. [CrossRef] [PubMed]

25. Cohen, S.M. New approaches for medicinal applications of bioinorganic chemistry. Curr. Opin. Chem. Biol. 2007, 11, 115-120. [CrossRef] [PubMed] 
26. Beard, M.C. Multiple Exciton Generation in Semiconductor Quantum Dots. J. Phys. Chem. Lett. 2011, 2, 1282-1288. [CrossRef] [PubMed]

27. Timmerman, D.; Izeddin, I.; Stallinga, P.; Yassievich, I.N.; Gregorkiewicz, T. Space-separated quantum cutting with silicon nanocrystals for photovoltaic applications. Nat. Photonics 2008, 2, 105-109. [CrossRef]

28. Yoffe, A.D. Low-dimensional systems: Quantum size effects and electronic properties of semiconductor microcrystallites (zero-dimensional systems) and some quasi-two-dimensional systems. Adv. Phys. 2002, 51, 799-890. [CrossRef]

29. Fuechsle, M.; Mahapatra, S.; Zwanenburg, F.; Friesen, M.; Eriksson, M.; Simmons, M. Spectroscopy of few-electron single-crystal silicon quantum dots. Nat. Nanotechnol. 2010, 5, 502-505. [CrossRef] [PubMed]

30. Bagolini, L.; Mattoni, A.; Fugallo, G.; Colomb, L. Quantum Confinement by an Order-Disorder Boundary in Nanocrystalline Silicon. Phys. Rev. Lett. 2010, 104, 176803. [CrossRef] [PubMed]

31. Beard, M.; Knutsen, K.P.; Yu, P.R.; Luther, J.M.; Song, Q.; Metzger, W.K.; Ellingson, R.J.; Nozik, A.J. Multiple exciton generation in colloidal silicon nanocrystals. Nano Lett. 2007, 7, 2506-2512. [CrossRef] [PubMed]

32. Cibulka, O.; Vorkotter, C.; Purkrt, A.; Holovsky, J.; Benedikt, J.; Herynkova, K. Comparison of Silicon Nanocrystals Prepared by Two Fundamentally Different Methods. Nanoscale Res. Lett. 2016, 11, 445. [CrossRef] [PubMed]

33. Tu, C.C.; Tang, L.; Huang, J.D.; Voutsas, A.; Lin, L.Y. Visible electroluminescence from hybrid colloidal silicon quantum dot-organic light-emitting diodes. Appl. Phys. Lett. 2011, 98, 213102. [CrossRef]

34. Gupta, A.; Swihart, M.; Wiggers, H. Luminescent Colloidal Dispersion of Silicon Quantum Dots from Microwave Plasma Synthesis: Exploring the Photoluminescence Behavior Across the Visible Spectrum. Adv. Funct. Mater. 2009, 19, 696-703. [CrossRef]

35. Godefroo, S.; Hayne, M.; Jivanescu, M.; Stesmans, A.; Zacharias, M.; Lebedev, O.; Van Tendeloo, G.; Moshchalkov, V. Classification and control of the origin of photoluminescence from Si nanocrystals. Nat. Nanotechnol. 2008, 3, 174-178. [CrossRef] [PubMed]

36. Chen, X.Y.; Lu, Y.F.; Wu, Y.H.; Cho, B.J.; Liu, M.H.; Dai, D.Y.; Song, W.D. Mechanisms of photoluminescence from silicon nanocrystals formed by pulsed-laser deposition in argon and oxygen ambient. J. Appl. Phys. 2003, 93, 6311-6319. [CrossRef]

37. Schmidt, J.U.; Schmidt, B. Investigation of Si nanocluster formation in sputter-deposited silicon sub-oxides for nanocluster memory structures. Mater. Sci. Eng. 2003, 101, 28-33. [CrossRef]

38. Kusova, K.; Cibulka, O.; Dohnalova, K.; Pelant, I.; Valenta, J.; Fucikova, A.; Zidek, K.; Lang, J.; Englich, J.; Matejka, P.; et al. Brightly Luminescent Organically Capped Silicon Nanocrystals Fabricated at Room Temperature and Atmospheric Pressure. ACS Nano 2010, 4, 4495-4504. [CrossRef] [PubMed]

39. Yuan, Z.; Nakamura, T.; Adachi, S.; Matsuishi, K. Improvement of Laser Processing for Colloidal Silicon Nanocrystal Formation in a Reactive Solvent. J. Phys. Chem. Lett. 2017, 121, 8623-8629. [CrossRef]

40. Nielsen, D.; Abdulhassan, L.; Alchihabi, M.; Al-Muhanna, A.; Host, J.; Nayfah, M.H. Current-less anodization of intrinsic silicon powder grains: Formation of fluorescent Si nanoparticles. J. Appl. Phys. 2007, 101, 114302. [CrossRef]

41. Nozaki, T.; Sasaki, K.; Ogino, T.; Asahi, D.; Okazaki, K. Microplasma synthesis of tunable photoluminescent silicon nanocrystals. Nanotechnology 2007, 18, 235603. [CrossRef]

42. Svrek, V.; Mariotti, D.; Kondo, M. Microplasma-induced surface engineering of silicon nanocrystals in colloidal dispersion. Appl. Phys. Lett. 2010, 97, 161502. [CrossRef]

43. Zhang, Q.; Bayliss, S.C.; Hutt, D.A. Blue photoluminescence and local-structure of Si nanostructures embedded in $\mathrm{SiO}_{2}$ matrices. Appl. Phys. Lett. 1995, 66, 1977-1979. [CrossRef]

44. Ray, M.; Hossain, S.M.; Klie, R.F.; Banerjee, K.; Ghosh, S. Free standing luminescent silicon quantum dots: evidence of quantum confinement and defect related transitions. Nanotechnology 2010, 21 (Suppl. 50), 505602. [CrossRef] [PubMed]

45. Xin, Y.Z.; Wakimoto, R.; Saitow, K. Synthesis of Size-controlled Luminescent Si Nanocrystals from (HSiO1.5)(n) Polymers. Chem. Lett. 2017, 46, 699-702. [CrossRef]

46. Wang, J.; Wu, X.L.; Li, T.H.; Chu, P.K. All-silicon solid films with highly efficient and tunable full-color photoluminescence. Scripta Mater. 2014, 76, 17-20. [CrossRef]

47. Vanhellemont, J.; De Gryse, O.; Clauws, P. Critical precipitate size revisited and implications for oxygen precipitation in silicon. Appl. Phys. Lett. 2005, 86, 221903. [CrossRef] 
48. Heintz, A.; Fink, M.; Mitchell, B. Mechanochemical synthesis of blue luminescent alkyl/alkenyl-passivated silicon nanoparticles. Adv. Mater. 2007, 19, 3984. [CrossRef]

49. Podhorodecki, A.; Misiewicz, J.; Gourbilleau, F.; Rizk, R. Absorption mechanisms of silicon nanocrystals in cosputtered silicon-rich-silicon oxide films. Electrochem. Solid-State Lett. 2008, 11, K31-K33. [CrossRef]

50. Zhou, Z.; Brus, L.; Friesner, R. Electronic structure and luminescence of1.1- and 1.4-nm silicon nanocrystals: Oxide shell versus hydrogenpassivation. Nano Lett. 2003, 3, 163-167. [CrossRef]

51. Kujala, J.; Slotte, J.; Tuomisto, F.; Hiller, D.; Zacharias, M. Si nanocrystals and nanocrystal interfaces studied by positron annihilation. J. Appl. Phys. 2016, 120, 145302. [CrossRef]

52. Li, H.P.; Xu, H.; Shen, X.P.; Han, K.; Bi, Z.T.; Xu, R.F. Size-, electric- field-, and frequency-dependent third-order nonlinear optical properties of hydrogenated silicon nanoclusters. Sci. Rep. 2016, 6, 28067. [CrossRef] [PubMed]

53. Chen, K.K.; Liao, K.; Casillas, G.; Li, Y.Y.; Ozin, G.A. Cationic Silicon Nanocrystals with Colloidal Stability, pH-Independent Positive Surface Charge and Size Tunable Photoluminescence in the Near-Infrared to Red Spectral Range. Adv. Sci. 2016, 3, 1500263. [CrossRef] [PubMed]

54. Botas, A.M.P.; Anthony, R.J.; Wu, J.; Rowe, D.J.; Silva, N.J.O.; Kortshagen, U.; Pereira, R.N.; Ferreira, R.A.S. Influence of the surface termination on the light emission of crystalline silicon nanoparticles. Nanotechnology 2016, 27, 325703. [CrossRef] [PubMed]

55. Yu, Y.; Hessel, C.M.; Bogart, T.D.; Panthani, M.G.; Rasch, M.R.; Korgel, B. Room Temperature Hydrosilylation of Silicon Nanocrystals with Bifunctional Terminal Alkenes. Langmuir 2013, 29, 1533-1540. [CrossRef] [PubMed]

56. Chandra, S.; Ghosh, B.; Beaune, G.; Nagarajan, U.; Yasui, T.; Nakamura, J.; Tsuruoka, T.; Baba, Y.; Shirahata, N.; Winnik, F.M. Functional double-shelled silicon nanocrystals for two-photon fluorescence cell imaging: Spectral evolution and tuning. Nanoscale 2016, 8, 9009-9019. [CrossRef] [PubMed]

57. Fujii, M.; Sugimoto, H.; Imakita, K. All-inorganic colloidal silicon nanocrystals-surface modification by boron and phosphorus co-doping. Nanotechnology 2016, 27, 262001. [CrossRef] [PubMed]

58. Sun, W.; Qian, C.X.; Chen, K.K.; Ozin, G.A. Silicon Nanocrystals: It's Simply a Matter of Size. Chemnanomat 2016, 2, 847-855. [CrossRef]

59. Han, P.G.; Poon, M.C.; Sin, K.O.; Wong, M. Photoluminescent porous polycrystalline silicon. In Proceedings of the Electron Devices Meeting, Clearwater Bay, Hong Kong, China, 1 July 1995.

60. Maxfield, F.R.; McGraw, T.E. Endocytic recycling. Nat. Rev. Mol. Cell. Biol. 2004, 5, 121-132. [CrossRef] [PubMed]

61. Yuli, I.; Oplatka, A. Cytosolic acidification as an early transductory signal of human neutrophil chemotaxis. Science 1987, 235, 340-342. [CrossRef] [PubMed]

62. Nishimura, H.; Ritchie, K.; Kasai, R.S.; Morone, N.; Sugimura, H.; Tanaka, K.; Sase, I.; Yoshimura, A.; Nakano, Y.; Fujiwara, T.K.; et al. Biocompatible fluorescent silicon nanocrystals for single-molecule tracking and fluorescence imaging. J. Cell Biol. 2013, 202, 967-983. [CrossRef] [PubMed]

63. Tian, B.; Cohen-Kami, T.; Qing, Q.; Duan, X.; Xie, P.; Lieber, C. Three-Dimensional, Flexible Nanoscale Field-Effect Transistors as Localized Bioprobes. Science 2010, 329, 830-834. [CrossRef] [PubMed]

64. Zhao, X.; Tapec-Dytioco, R.; Tan, W. Ultrasensitive DNA detection using highly fluorescent bioconjugated nanoparticles. J. Am. Chem. Soc. 2003, 125, 11474-11475. [CrossRef] [PubMed]

(C) 2017 by the authors. Licensee MDPI, Basel, Switzerland. This article is an open access article distributed under the terms and conditions of the Creative Commons Attribution (CC BY) license (http://creativecommons.org/licenses/by/4.0/). 